\title{
The Occurrence of Calcium Oxalate Crystals and Distribution of Arabinogalactan Proteins (AGPs) in Ovary Cells During Fragaria $x$ ananassa (Duch.) Development
}

\author{
Agata Leszczuk ${ }^{1} \cdot$ Jerzy Wydrych ${ }^{2} \cdot$ Ewa Szczuka $^{3}$
}

Received: 8 December 2017 / Accepted: 27 December 2018 / Published online: 3 January 2019

(c) The Author(s) 2019

\begin{abstract}
In this study, the presence of calcium oxalate crystals and distribution of arabinogalactan proteins (AGPs) in the ovary of Fragaria $\mathrm{x}$ ananassa (Duchesne) were investigated. The arrangement of the AGP epitopes was analyzed using immunohistochemistry techniques with JIM13, JIM15, and MAC207 monoclonal antibodies. To confirm the immunofluorescence studies, experiments at the subcellular level were performed with the immunogold method using transmission electron microscopy. We observed calcium oxalate crystals as druses in the middle layer of the ovary, which created a distinct ring-like immunofluorescence pattern around the ovule, indicating the presence of AGP epitopes. We propose hypotheses concerning the roles of calcium oxalate crystals in ovaries: the occurrence of crystals in the external part of the ovary may constitute a mechanical barrier against herbivores (1) the presence of AGPs in close proximity to calcium oxalate crystals may support their role as a calcium depository, which is important for the developing embryo and seed coat formation as well as in the interaction between pollen tubes and female gametophyte during sexual plant reproduction (2).
\end{abstract}

Keywords Arabinogalactan proteins · Calcium oxalate crystals · Fragaria x ananassa - Immunofluorescence labeling · Immunogold method

\section{Introduction}

The occurrence of calcium oxalate crystals has been a subject of many studies among all taxonomic levels of diverse group of organisms. Crystal $(\mathrm{CaOx})$ formation is a basic process in various tissues and organs. Their accumulation as intracellular or extracellular deposits has been described

Agata Leszczuk

a.leszczuk@ipan.lublin.pl

Jerzy Wydrych

jerzy.wydrych@poczta.umcs.lublin.pl

Ewa Szczuka

ewa.szczuka@poczta.umcs.lublin.pl

1 Institute of Agrophysics, Polish Academy of Sciences, Doświadczalna 4, 20-290 Lublin, Poland

2 Department of Comparative Anatomy and Anthropology, Maria Curie-Skłodowska University, Akademicka 19, 20-033 Lublin, Poland

3 Department of Plant Anatomy and Cytology, Maria Curie-Skłodowska University, Akademicka 19, 20-033 Lublin, Poland in leaves (Nakata 2012; Konyar et al. 2014), stems (Meric 2009), anthers (Iwano et al. 2004; Gębura and Winiarczyk 2016), and seeds (Ilarslan et al. 2001). Calcium oxalate crystal has a defined shape: crystal sand, druse, styloid, prismatic, and raphide (Raman et al. 2014). Based on their morphology, size, and place of accumulation, multiple functions have been proposed, which mainly demonstrated their roles in the mechanism of regulating calcium levels, plant protection, and detoxification of heavy metals. The crystal functions have been widely reviewed extensively (Nakata 2003; Franceschi and Nakata 2005; Tooulakou et al. 2016).

So far, there have been few studies about the occurrence and functions of crystals in ovaries. One of them conducted by Coté (2009) describes crystals in the wall of the Dieffenbachia seguine (Araceae) gynoecium and their absence in the ovules and stigma. The dense concentration of small raphides and druses has been connected with their function as deterrents to herbivores causing abrasion of mouthparts (Coté 2009). In investigations of a few Themidaceae and Hyacinthaceae species, raphide bundles were reported to be present in the ovary wall (Berg 2003). Nevertheless, knowledge on the role of crystals in ovaries is still lacking. 
Webb and coworkers (1995) carried out isolation of crystals along with associated intravacuolar matrix from leaves of grape. Elemental analysis of the water-soluble phase showed that it also contained polymers with glucuronic acid linkages, typical for complex carbohydrates of $\mathrm{N}$-linked proteoglycans. The data about the organic matrix associated with crystals are discussed in detail in relation to the role of specific proteins in influencing crystal morphology and crystal cell development. Moreover, proteins of the water-soluble matrix may have a potential role in mediating exchange between the cytoplasm and the crystal chamber, controlling passage of calcium (Webb et al. 1995). Similarly, interactions of macromolecules with calcium oxalate crystals in tomato and tobacco plants were studied by Bouropoulos et al. (2001). Extracted crystal-associated macromolecules were found to influence the formation of crystals and might be responsible for their unique shape. Furthermore, the accumulation of the examined macromolecules may exert an effect on promotion of nucleation of calcium oxalate in vitro (Bouropoulos et al. 2001). Li and coworkers (2003) conducted an experiment demonstrating the occurrence of organic matrix correlated with calcium oxalate crystals, which has Ca- and oxalate-binding properties. Studies about localization of matrix proteins in mesophyll cells of the leaf confirmed their association with developing crystals and indicated a basic of physiological mechanism for exploitation of large amounts of calcium in higher plants (Li et al. 2003).

One of the groups of proteoglycans that have a possibility of binding calcium ions is arabinogalactan proteins (AGPs). They are widespread in plant tissues as structural components of the extracellular matrix (ECM) of cell walls. AGPs are characterized by a few specific features, for example, a high proportion of carbohydrate chains, up to $90 \%$, heterogeneity of their polysaccharide substituents, and addition of the C-terminal sequence GPI that anchors the AGPs molecule to the outer leaflet of the plasma membrane (Seifert and Roberts 2007). Referring to the role of tightly bound AGP-Ca ${ }^{2+}$ by creation of a periplasmic reservoir of calcium ions, Lamport et al. (2014) elucidated AGP functions in multiple plant processes. With other cellular messengers (auxin, $\mathrm{Ca}^{2+}$ ), AGPs participate in integration of signaling pathways. Interestingly, the AGP and calcium interaction may be a crucial determinant of calcium ion gradient during pollen tube guidance. Furthermore, AGP-Ca ${ }^{2+}$ dissociation in the transmitting tissue may generate a signal guarding the pollen tube to the ovary and ovule (Coimbra and Duarte 2003; Lamport et al. 2014).

The aim of the current work was to describe the localization of calcium oxalate crystals in $F$. x ananassa ovaries and the analysis of AGPs presence in close proximity to $\mathrm{CaOx}$. Experiments performed at the cellular and subcellular levels allowed the identification of unique arrangement of druses in ovary cells. The localization of calcium oxalate crystals may be related to basic mechanisms of physiological and developmental processes taking place in plants. To clarify the unusual formation of crystals and the specific pattern of AGPs epitopes distribution, we proposed hypotheses for elucidation of this interesting phenomenon.

\section{Materials and Methods}

Ovaries of Fragaria x ananassa (Duchesne) cv. 'Mount Everest' were used in all experiments. Material was collected from plants cultivated in a greenhouse at the Maria Curie-Skłodowska University. Studies were performed on flower buds after anthesis during three flowering seasons from 2014 to 2016.

\section{Analysis of Ovary Morphology: Scanning Electron Microscopy (SEM)}

To describe the ovary morphology and its placement on the receptacle, SEM analyses of flower buds were carried out after removal of flower petals. The research material was fixed in $2.5 \%$ glutaraldehyde in phosphate buffer and washed in distilled water. After dehydration in increasing concentrations of ethanol, drying in a critical point dryer was carried out using liquid $\mathrm{CO}_{2}$ (K850 EMITECH, UK). The material was mounted on aluminum stubs, coated with gold using a sputter coater (K550X EMITECH, UK), and analyzed under a scanning electron microscope (Vega 3 Tescan, UK).

\section{Fixation and Embedding for Anatomical Observations}

Isolated ovaries were fixed in a solution of $4 \%$ paraformaldehyde and $0.5 \%$ glutaraldehyde in phosphate buffer $(0.1 \mathrm{M}, \mathrm{pH}$ 7.2), placed under vacuum for $2 \mathrm{~h}$, and kept at $4{ }^{\circ} \mathrm{C}$ for $24 \mathrm{~h}$. The fixed material was washed and dehydrated in a graded ethanol series. After that, standard LR White embedding was conducted, with resin infiltration and polymerization in gelatine capsules at $55^{\circ} \mathrm{C}$ for $48 \mathrm{~h}$. Then, the LR White blocks were sectioned with the use of an ultramicrotome (Leica Reichert Ultracut S, Austria). For LM, CLSM, 1- $\mu$ m-thick sections were obtained with the use of a glass knife and placed on poly-L-lysine-coated glass slides (Sigma, USA). For TEM observations, ultrathin sections (65-nm thick) were cut using a diamond knife and mounted on $100 \mathrm{MESH}$ formvar-coated nickel grids (Sigma, USA).

\section{Localization of AGPs in Ovary Cells: Immunofluorescence Labeling (CLSM)}

Localization of AGPs epitopes was determined in performance immunocytochemical reactions using monoclonal 
antibodies that recognize the structurally complex carbohydrate moiety of AGP. The experiment was conducted using JIM13, which recognizes arabinogalactan protein epitope containing trisaccharide $\beta$-D-GlcA-(1,3)- $\alpha$-DGalA(1,2)- $\alpha$ L-Rha (Knox et al. 1991), JIM15 (epitope not determined, according to CarboSource and Yates et al. 1996), and MAC207, which recognizes the epitope $\beta$-GlcA- $(1,3)-\alpha-$ GalA(1,2)-Rha (Pennel et al. 1989).

To avoid nonspecific binding of antibodies, sections prepared for immunofluorescence labelling were preincubated with bovine serum albumin (BSA) for $30 \mathrm{~min}$. After washing in phosphate buffer, the slides were incubated with a primary antibody diluted 1:50 in a blocking solution for $12 \mathrm{~h}$ at $4{ }^{\circ} \mathrm{C}$ and with a secondary antibody diluted 1:200 in the same buffer for $12 \mathrm{~h}$ at $4{ }^{\circ} \mathrm{C}$ in the dark. To obtain a fluorescence signal, a secondary FITC-conjugated antibody (Sigma, USA) was used. After the reaction, the glass slides with the sections were washed in deionized water and enclosed in Dako Fluorescent Mounting Medium (Sigma, USA).

Control reactions were performed by omitting incubation with antibodies against AGPs. Additionally, we examined the material for autofluorescence. All parameters (that is, laser intensity, gain) were kept constant for all experiments. The prepared slides were analyzed and imaged with a confocal laser scanning microscope (Zeiss Axiovert 200M equipped with an LSM 5 Pascal laser scanning head, Germany).

\section{Localization of AGPs in Ovary Cells at the Subcellular Level: Immunogold Method (TEM)}

Sections mounted on grids were washed a few times in deionized water and then incubated in the blocking solution containing 1\% BSA in phosphate buffer for $1 \mathrm{~h}$ at room temperature. Incubation with the primary antibody-recognized sugar epitopes of AGPs (diluted 1:10 in the blocking solution) was conducted for $3 \mathrm{~h}$ at $37^{\circ} \mathrm{C}$. After that time, the grids were washed a few times in deionized water and in the blocking solution. To observe the presence of AGPs using transmission electron microscopy, we carried out incubation with the secondary antibody (diluted 1:50 in the blocking solution) conjugated with gold particles (Sigma, USA) for $1 \mathrm{~h}$ at $37^{\circ} \mathrm{C}$. After washing in deionized water, the samples were stained with $1 \%$ uranyl acetate for 5 min and Reynold's reagent for $1 \mathrm{~min}$. The observations were performed using a transmission electron microscope operating at $120 \mathrm{kV}$ acceleration voltage (ZEISS LEO 912 AB, Germany).

\section{Distribution of Calcium lons: Cytochemical Staining (LM)}

To study the presence of calcium ions in ovary cells with calcium oxalate crystals, the sections were stained on a glass slide with $1 \%$ Alizarin red for $5 \mathrm{~min}$ at $70{ }^{\circ} \mathrm{C}$. To visualize the presence of crystals in a single cell staining with $0.5 \%$ toluidine blue was carried out for $2 \mathrm{~min}$ at $55^{\circ} \mathrm{C}$. Next, the stained ovaries were crushed with a coverslip in a drop of $50 \%$ glycerin. The sections were analyzed and imaged using an N-800M microscope (Novel, China).

All microscopic examinations were performed in a minimum of 50 sections. Photographs and the scheme were edited using the CorelDrawX6 graphics program.

\section{Results}

\section{Placement of Ovaries on the Receptacle in the Fragaria $x$ ananassa (Duch.) Flower}

To identify the reason for the occurrence and physiological role of calcium oxalate crystals, flower buds of Fragaria x ananassa were analyzed. The flower of the examined cultivar is typical for the Fragaria genus (Ariza et al. 2015; Hollender et al. 2011) with five petals and sepals around the gynoecium and numerous anthers (Fig. 1a). The raised receptacle is densely covered by numerous ovaries with ovules, almost several dozen in each flower bud (Fig. 1b). Each pistil consists of ovary, a style, and a stigma (Fig. 1c, d). Inside the ovary, there is only one ovule surrounded by a single integument and a six-layered ovary wall (Fig. 1e). After development, the ovary layers in the globular embryo stage are formed by sclerenchyma cells, which form a seed coat (Fig. 1f).

\section{Localization of AGPs in Ovary Cells with Calcium Oxalate Crystals}

The studies based on the use of antibodies against AGP epitopes showed the presence of AGPs mainly in the cell walls of a developing embryo sac and ovary layers. In an early stage of development-the tetrad stage, immunofluorescence labeling confirmed the localization of AGP epitope recognized by JIM13 mAb in its individual cells (Fig. 2a). Similarly, single fluorescence signals were observed in the ovary cells after the reaction with JIM15 $\mathrm{mAb}$ (Fig. 2b). In case of reaction with MAC207 antibody, fluorescence was not visible (Fig. 2c). In the ovary at a more advanced stage of development, with an ovule enclosed in the mature embryo sac, the observed fluorescence was stronger and visible in the middle layer of the ovary wall (Fig. 2d). After labeling with JIM15 mAb, the AGP epitope was localized in the same part of the ovary as well (Fig. 2e). Moreover, fluorescence indicating the presence of AGPs was noticeable in the embryo sac wall and nucellus cells (Fig. 2d, e). After reaction with MAC207, the fluorescence signal was very weak and appeared only 
in part of the embryo sac walls (Fig. 2f). The most appreciable results were reported in the ovary with an ovule ready for double fertilization, with a female gametophyte consisting of seven cells. Very strong fluorescence was observed in the embryo sac wall and especially in the ovary cells, but only in one of its layers. The signal viewed created a unique ring-like shape sheath surrounding the ovule without a signal in the ovary part connected with the pistil (Fig. 2g, h). Epitope recognized by MAC207 mAb was localized in cell walls of ovary and ovule. However, the specific pattern observed after reaction with JIM13 and JIM15 mAbs did not occur (Fig. 2i). The reaction with omitting the incubation with the antibody against AGPs showed no fluorescence signal and no autofluorescence (Fig. 2j).
Fig. 2 Presence of AGP epitopes in F. x ananassa ovaries. Distribution of AGP epitopes in early-developed ovary cells containing calcium oxalate crystals (arrows). Noticeable a few parts of the middle ovary layer with a stronger fluorescence signal after reaction with JIM13 (a). Similar localization of AGP epitopes after labeling with JIM15 (b). Lack of fluorescence signal after labeling with MAC207 (c). Localization of AGP epitopes recognized by JIM13 mAb in the ovary with an ovule in the mature embryo sac stage. Visible characteristic ring-like pattern in one of the layers of the ovary (arrows, d). Similar distribution of AGP epitopes after reaction with JIM15 $\mathrm{mAb}(\mathbf{e})$. Weak fluorescence in the whole surface of ovary after labeling with MAC207 (f). Ovary with an ovule during double fertilization. Strong signal of fluorescence after reaction with JIM13 (g) and JIM15 (h) mAbs in an embryo sac and in a single middle layer of the ovary (arrows). Fluorescence after reaction with MAC207 mAb in all cell walls of ovary (i). Control reaction carried out without the primary antibody against AGP (j). CLSM. Scale bars: $\mathbf{a}-\mathbf{i}=100 \mu \mathrm{m}$; $\mathbf{j}=20 \mu \mathrm{m}$. ch chalaza, $m i$ micropyle, $n u$ nucellus, $o v$ ovary wall
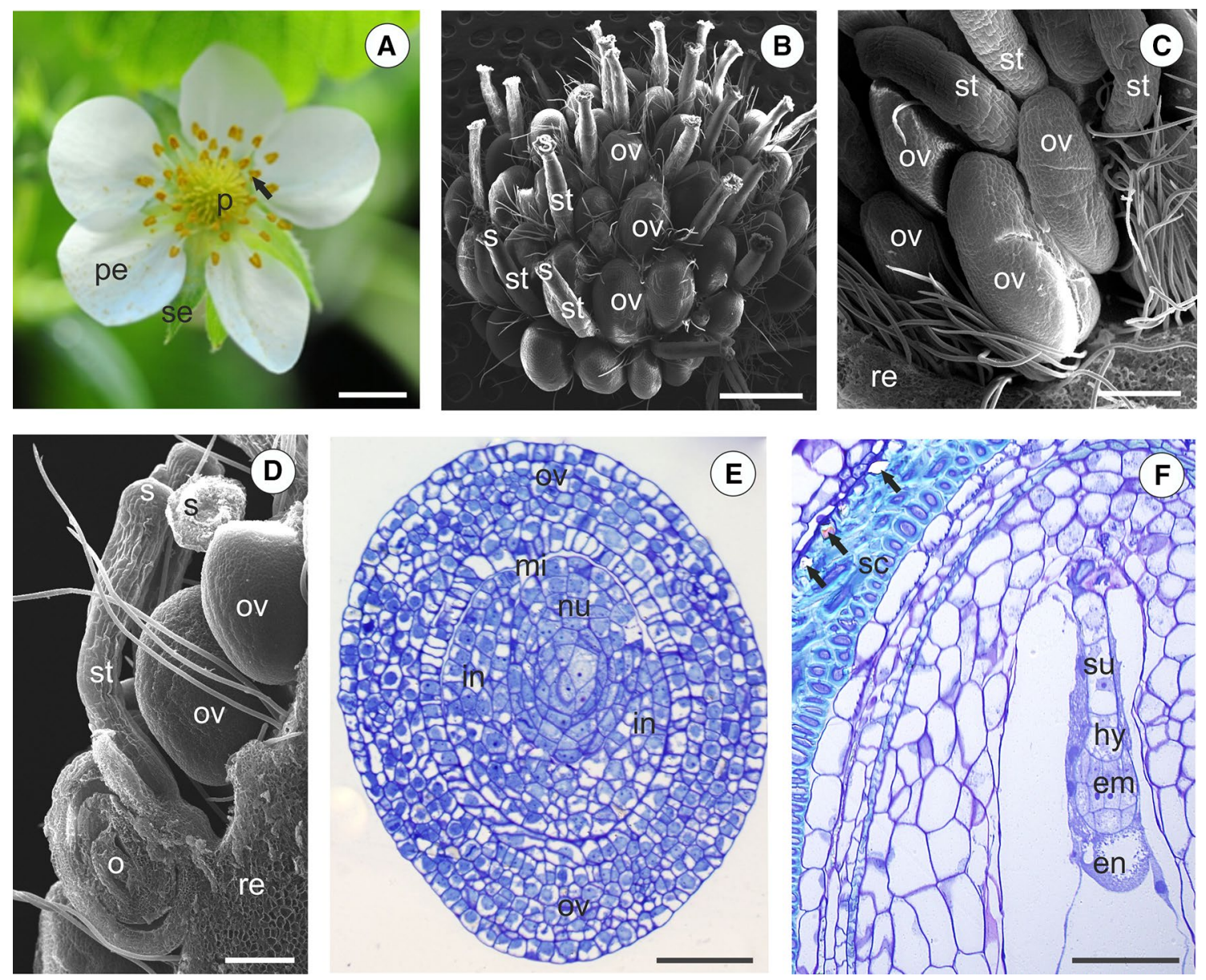

Fig. 1 Morphological features of Fragaria x ananassa cv. 'Mount Everest' flower. Flower of $F$. x ananassa with numerous pistils (p) and stamens (arrow) (a). Flower bud with multiple ovaries (ov) on a raised receptacle. SEM (b). Magnification of ovaries (ov) closely placed on the receptacle (re). SEM (c). Section through the ovary with a visible ovule (o) and a pistil with a style (st) and a stigma (s). SEM (d). Longitudinal section of the ovary at an early step of development. Ovary wall (ov) consisting of six cell layers, which cover the ovule nucellus. Visible single integument (unitegmic) (in), formed micropyle (mi). Staining with toluidine blue. LM (e). Toluidine bluestained section with a part of ovary and a developing embryo. Visible sclerenchyma cells forming a seed coat filled by calcium oxalate crystals (arrows). LM (f). Scale bars: $\mathbf{a}=5 \mathrm{~mm}, \mathbf{b}=500 \mu \mathrm{m}, \mathbf{c}=200 \mu \mathrm{m}$, $\mathbf{d}=150 \mu \mathrm{m}, \mathbf{e}, \mathbf{f}=50 \mu \mathrm{m}$. em embryo, en endosperm, hy hypophysis, in integument, $m i$ micropyle, $n u$ nucellus, $o$ ovule, $o v$ ovary, $p$ pistil, pe petal, re receptacle, $s$ stigma, sc sclerenchyma cells, se sepal, st style, $s u$ suspensor 

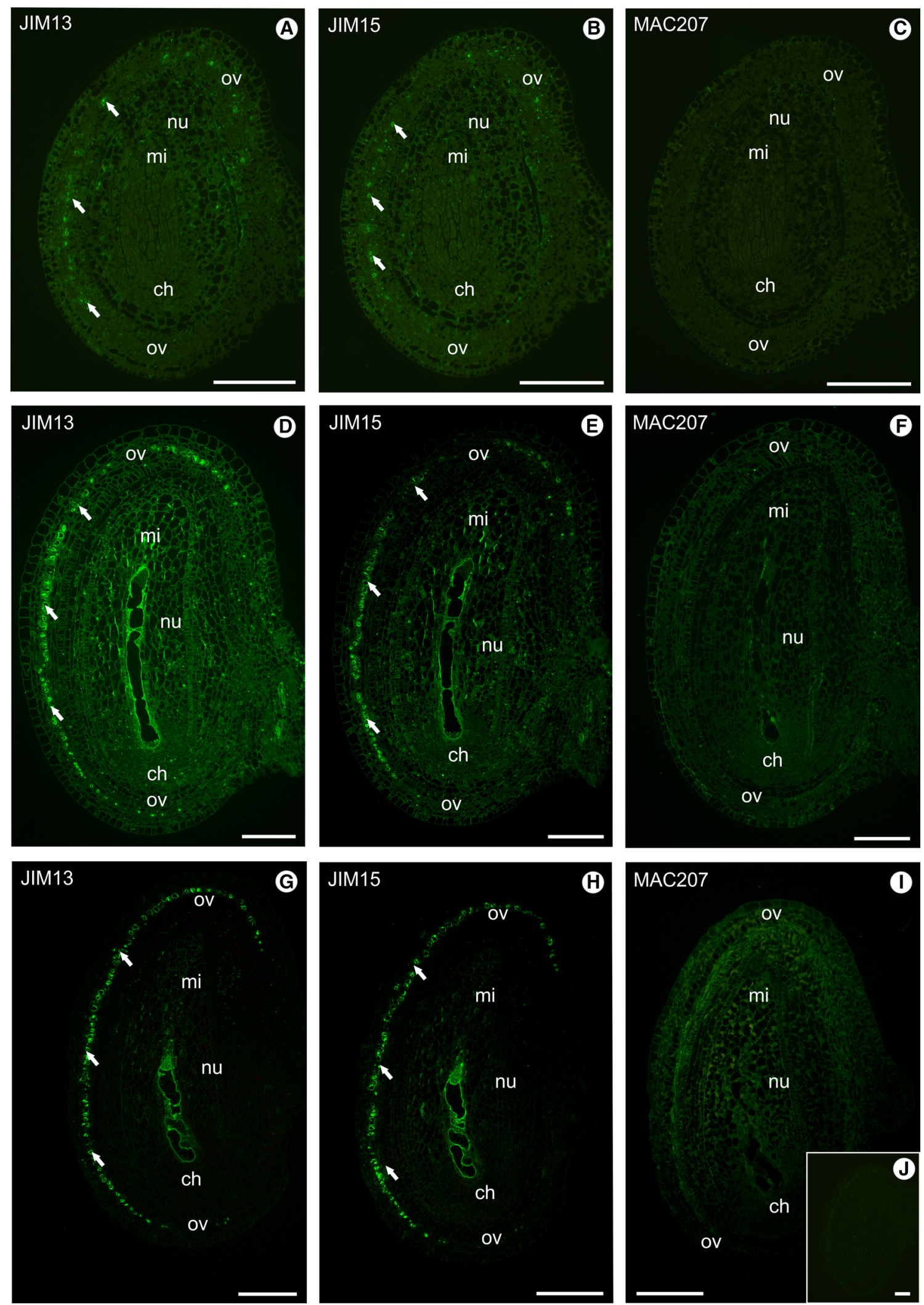
Scheme 1 Schematic representation of location of ovaries on the receptacle of Fragaria $\mathrm{x}$ ananassa (Duch.). Magnification of a single ovary with arrangement of calcium oxalate crystals-druses (arrows) in its middle wall layer. $c h$ chalaza, es embryo sac, $m i$ micropyle, $n u$ nucellus, ov ovary, re receptacle, $s$ stigma, st style

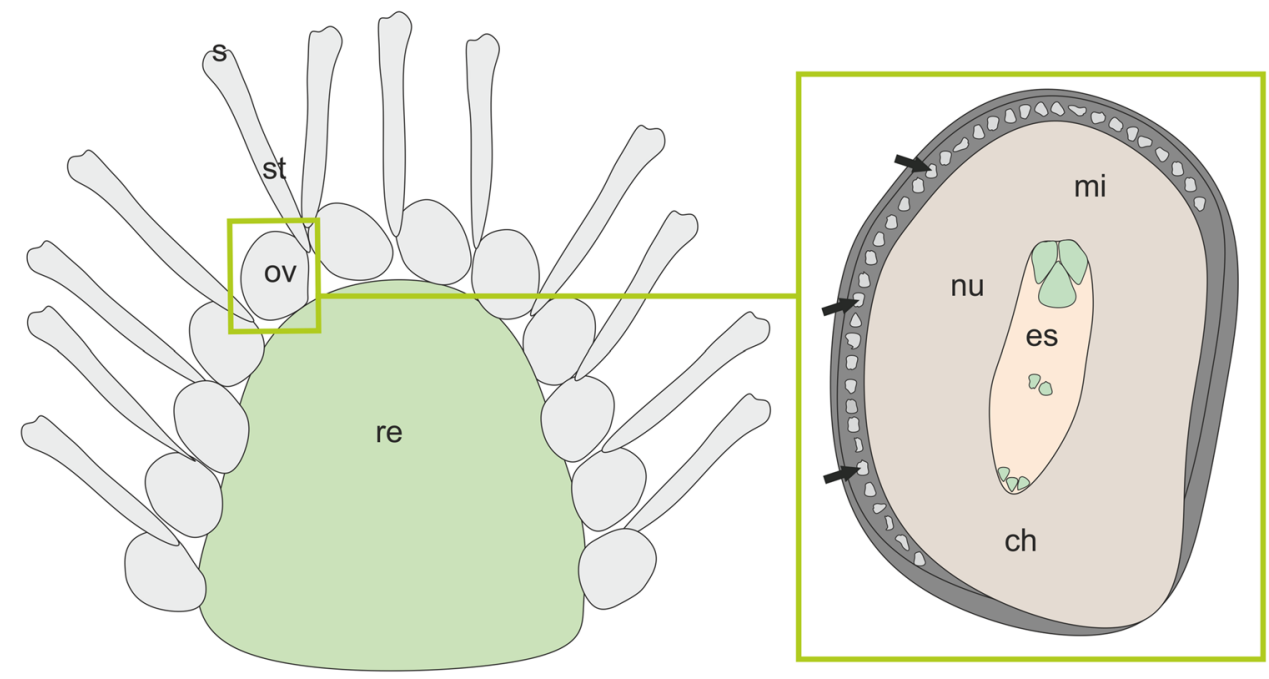

A scheme was drawn up to visualize the arrangement of the ovaries, their placement on the receptacle, and the presence of calcium oxalate crystals in the single ovary (Scheme 1).

\section{Features of Druses in Ovary Cells}

The immunofluorescence labeling of AGPs showed the presence of their epitopes in cells with calcium oxalate crystals. The longitudinal sections of the ovary showed its structure-a few tightly adjacent cells forming regular layers. The cells of the middle layer were filled by crystals. Immunofluorescence labeling pointed at the distribution of AGP epitopes in close proximity to crystals (Fig. 3a, b). To study the features of the ovary layer with crystals, TEM observations using immunogold labeling procedures were carried out. The crystals filled a significant part of the vacuoles and occurred as druses with rectangular cross sections (Fig. 3c, d). The immunogold method confirmed AGP localization in the periphery of the druses. Gold particles were noticeable inside the vacuole and near the periphery of the crystals (Fig. 3e). Alizarin red used for calcium localization showed very specific staining (Fig. 3f, g, h), which demonstrated that the examined ions were present in the crystals as well as near their edge, and their localization coincided with the occurrence of AGP epitopes (Fig. 3i).

\section{Discussion}

In Rosaceae family, crystals have been observed only in the leaf of Crataegus (Demiray 2007) and Prunus virginiana (Lersten and Horner 2004). In this study, crystals were observed in the ovary wall of $F$. x ananassa. Moreover, their accumulation was correlated with the stage of ovary development. At first, single crystals were observed in early-developed ovaries during the initial stages of megasporogenesis. The characteristic pattern of occurrence of the druses was noticeable in an ovary with a mature embryo sac, getting ready for double fertilization.

Calcium oxalate crystals in plants were described as a protection against herbivory and tissue support. Accumulation of crystals in tropical plants was justified by their participation in the defense mechanism and their role as a feeding repellent. In Pancratium sickenbergeri leaves, crystals are an important part of an appropriate strategy toward environmental unpredictability (Ruiz et al. 2002). In the case of reproductive organs, crystal formation was observed in developing seeds of Glycine max. The authors described cells of the outer and inner integument of a young seed containing numerous crystals. The crystal cell layer in the seed may protect the embryo against external pests (Ilarslan et al. 2001). Similarly, the presence of crystals in $F$. x ananassa ovaries may be initiated in response to diverse environments and physical conditions. The observed druses are located in the convex part of the ovary, which is directly exposed to herbivores. The continuous layer of ovary cells filled by crystals formed a mechanical reinforcement and support tissue. It is a passive way of deterrence of insects.

Some studies indicate that the formation of calcium oxalate crystals is a consequence of many physiological processes in plant cells. As has been suggested (Mazen et al. 2003), the occurrence of crystals is related to the mechanism of regulating the levels of calcium ions in plants cells. Their form, size, and amount are correlated with changes in the calcium concentration in the environment. Druses are formed due to high fluctuations in calcium levels-as the concentration increases, the size and number of crystals increases dramatically (Nakata 2003). Therefore, druses as deposits of calcium in developing ovaries may contribute to retention of ions for later use by the growing embryo. The 

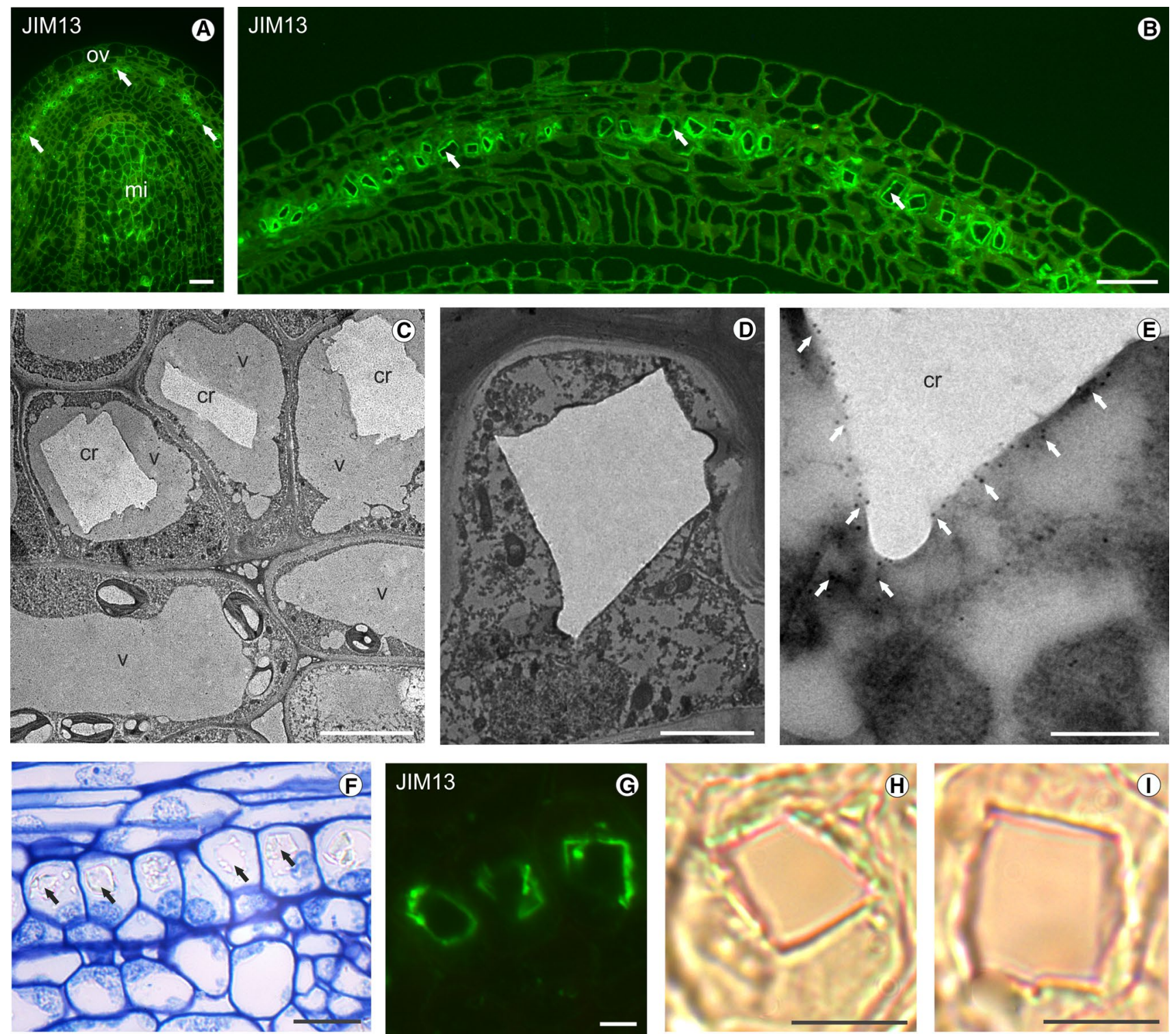

Fig. 3 Features of calcium oxalate crystals in ovary cells. Localization of AGP epitopes recognized by JIM13 mAb in ovary layers (ov) with calcium oxalate crystals (arrows). CLSM (a). Magnification of the ovary layers. Visible intensive fluorescence in cells with calcium oxalate crystals (arrows), indicating the presence of AGP epitopes. CLSM (b). Ultrastructure of ovary cells with calcium oxalate crystals (cr) in the vacuole (v). TEM. (c). Single cell filled by a CaOx crystal (druse). TEM (d). Immunogold reaction confirming the presence of AGPs on the edge of a $\mathrm{CaOx}$ crystal (cr, arrows). TEM (e). Cal-

place of accumulation - the external part of the ovary, that is, the outer integument, confirmed the role in ion storage, which is necessary for embryo development and seed coat formation.

Currently, general strategies and many mechanisms supporting the pollen tube pathway in the ovary have been elucidated. In the case of multi-ovulated species, the absence of a marked path to the ovule entrance is the cause of avoidance cium ion deposits near $\mathrm{CaOx}$ crystals (arrows) in ovary cells. Alizarin red and toluidine blue staining. LM (f). Strong signal of fluorescence after reaction with JIM13 mAb on the edge of crystals. CLSM (g). Single cell filled by a druse. Red color on the edge of the crystal indicating the presence of calcium ions. Alizarin red staining. LM $(\mathbf{h}, \mathbf{i})$. Scale bars $\mathbf{a}, \mathbf{b}=20 \mu \mathrm{m}, \mathbf{c}, \mathbf{d}=5 \mu \mathrm{m}, \mathbf{e}=250 \mathrm{~nm}, \mathbf{f}-\mathbf{i}=10 \mu \mathrm{m}$. ch chalaza, $c r$ calcium oxalate crystal, $m i$ micropyle, $n u$ nucellus, $o v$ ovary wall, $v$ vacuole

of a number of ovaries by the pollen tube. The choice of the appropriate ovule and the mechanism of this phenomenon has not been explained (Herrero 2000). Interestingly, in $F$. $\mathrm{x}$ ananassa, crystals do not occur in the part of the ovary connected with the pistil and the unique pattern of immunofluorescence is interrupted. Their absence in the funiculus and entry of the pollen tube may be an adjustment of the ovary to the male-female interaction. 
All presented hypotheses referring to the presence of crystals in response to the changeable environment are indisputable but the distribution of AGPs in close proximity to crystals is equally important. In previous studies, authors identified proteins associated with calcium oxalate crystals influencing the morphology of crystals (Webb et al. 1995). Immunofluorescence labeling performed in these studies showed strong fluorescence near crystals, indicating the presence of AGP epitopes. AGPs are generally considered as proteoglycans involved in developmental processes (Showalter 2001; Seifert and Roberts 2007; Pereira et al. 2015; Leszczuk and Szczuka 2018), but AGPs have never been observed in a close association with calcium oxalate crystals. Clearly, AGPs have a possibility to bind calcium ions and act as calcium capacitors, which have an impact on plant growth and development (Lamport and Várnai 2013). The formation of calcium oxalate crystals and the close distribution of AGPs may be correlated with the trophic effect of the calcium gradient on germinating pollen tubes. AGP participation in a few communication steps between the male gametophyte and the female reproductive tissue is well known. As a key component, AGPs are involved in the interaction during the growth of the pollen tube through the female flower tissue and the mechanism of pollen tube reception and double fertilization (Pereira et al. 2016). The secretory pattern of AGPs in both the stigma and the obturator was described in Malus x domestica, where the examined proteins play a clear role in pollen tube passage and mark access to the ovule (Losada and Herrero 2017). Regarding $F$. x ananassa, the AGP role in pollen tube guidance with implications in $\mathrm{Ca}^{2+}$ signaling is more reasonable because of the receptacle structure. On the raised receptacle, there are numerous ovaries with ovules, and all of them compete for the pollen tube entry. Moreover, AGP epitopes labelled with JIM13 and JIM15 mAbs in cells filled by crystals were noticeable in ovaries with ovules in advanced stages of development, ready for fertilization. Our data are a new example confirming the role of AGPs as an attractant for directing the pollen tube approach to the ovule. Furthermore, the presented observation is similar to the results reported by Lamport et al. (2014), where the interaction of AGPs associated with calcium ions was observed in the transmitting track tissue with the moving pollen tube. It has been shown that AGPs- $\mathrm{Ca}^{2+}$ determines the calcium gradient and thus directs the pollen tube toward the ovule micropyle. Unfortunately, the mechanism of regulation of the availability and release of calcium ions for the growing pollen tube is still unclear (Pereira et al. 2016). The necessity of deposition of calcium ions in ovaries by crystal formation may be a solution for ion retention and use thereof as intracellular signals accumulated in vacuoles and released into the cytoplasm.
To sum up, we propose three hypotheses concerning the roles of calcium oxalate crystals in ovaries with the close location of AGPs:

Hypothesis 1 'mechanical protection' The occurrence of crystals in the external part of the ovary may constitute a mechanical barrier against herbivores. The tissue support mentioned above is essential for protection of the ovule and, in this way, all developmental events, leading to formation of wholesome seeds.

Hypothesis 2 'storage of calcium ions' Calcium oxalate crystals in the ovary are responsive to fluctuations in the concentration of calcium in the plant environment.

Hypothesis 3 'attractant for growing pollen tubes' Crystals associated with AGPs may serve dual functions: deposition of calcium ions important for the developing embryo and seed coat formation as well as involvement in the earliest events during sexual plant reproduction-the interaction between pollen tubes and female gametophyte getting ready for fertilization.

Author Contribution AL conducted all experiments, interpreted data, and wrote the manuscript; JW helped in immunofluorescence imaging, ES helped in manuscript preparation.

\section{Compliance with Ethical Standards}

Conflict of interest The authors have no conflicts of interest to declare.

Open Access This article is distributed under the terms of the Creative Commons Attribution 4.0 International License (http://creativeco mmons.org/licenses/by/4.0/), which permits unrestricted use, distribution, and reproduction in any medium, provided you give appropriate credit to the original author(s) and the source, provide a link to the Creative Commons license, and indicate if changes were made.

\section{References}

Ariza MT, Soria C, Martínez-Ferri E (2015) Developmental stages of cultivated strawberry flowers in relation to chilling sensitivity. AoB Plants 7:1-12

Berg RY (2003) Development of ovule, embryo sac, and endosperm in Triteleia (Themidaceae) relative to taxonomy. Am J Bot 90(6):937-948

Bouropoulos N, Weiner S, Addadi L (2001) Calcium oxalate crystals in tomato and tobacco plants: morphology and in vitro interactions of crystal-associated macromolecules. Chem Eur J 7(9):1881-1888

Coimbra S, Duarte C (2003) Arabinogalactan proteins may facilitate the movement of pollen tubes from the stigma to the ovules in Actinidia deliciosa and Amaranthus hypochondriacus. Euphytica 133:171-178 
Coté GG (2009) Diversity and distribution of idioblasts producing calcium oxalate crystals in Dieffenbachia seguine (Araceae). Am J Bot 96(7): 1245-1254

Demiray H (2007) Calcium oxalate crystals of some Crataegus (Rosaceae) species growing in Aegean region. Biologia 62(1):46-50

Franceschi VR, Nakata PA (2005) Calcium oxalate crystals in plants: formation and function. Annu Rev Plant Biol 56:41-71

Gębura J, Winiarczyk K (2016) A study on calcium oxalate crystals in Tinantia anomala (Commelinaceae) with special reference to ultrastructural changes during anther development. J Plant Res 129:685-695

Herrero M (2000) Changes in the ovary related to pollen tube guidance. Ann Bot 85:79-85

Hollender CA, Geretz AC, Slovin JP, Liu Z (2011) Flower and early fruit development in a diploid strawberry, Fragaria vesca. Planta 235(6):1123-1139

Ilarslan H, Palmer G, Horner HT (2001) Calcium oxalate crystals in developing seeds of soybean. Ann Bot 88:243-257

Iwano M, Entani T, Shiba H, Takayama S, Isogai A (2004) Calcium crystals in the anther of Petunia: the existence and biological significance in the pollination process. Plant Cell Physiol 45(1):40-47

Knox JP, Linstead PJ, Peart J, Cooper C, Roberts K (1991) Developmentally regulated epitopes of cell surface arabinogalactan proteins and their relation to root tissue pattern formation. Plant J 1:317-326

Konyar ST, Öztürk N, Dane F (2014) Occurrence, types and distribution of calcium oxalate crystals in leaves and stems of some species of poisonous plants. Bot Stud 55(32):1-9

Lamport DTA, Várnai P (2013) Periplasmic arabinogalactan glycoproteins act as a calcium capacitor that regulates plant growth and development. New Phytol 197:58-64

Lamport DTA, Várnai P, Seal CE (2014) Back to the future with the AGP-Ca ${ }^{2+}$ flux capacitor. Ann Bot 114:1069-1085

Lersten N, Horner HT (2004) Calcium oxalate crystal macropattern development during Prunus virginiana (Rosaceae) leaf growth. Can J Bot 82(12):1800-1808

Leszczuk A, Szczuka E (2018) Arabinogalactan proteins: Immunolocalization in the developing ovary of a facultative apomict Fragaria. $\mathrm{x}$ ananassa (Duch.). Plant Physiol Biochem 123:24-33

Li X, Zhang D, Lynch-Holm VJ, Okita TW, Franceschi VR (2003) Isolation of a crystal matrix protein associated with calcium oxalate precipitation in vacuoles of specialized cells. Plant Physiol 133:549-559
Losada JM, Herrero M (2017) Pollen tube access to the ovule is mediated by glycoprotein secretion on the obturator of apple (Malus X domestica, Borkh). Ann Bot 119:989-1000

Mazen AMA, Zhang D, Franceschi VR (2003) Calcium oxalate formation in Lemma minor: physiological and ultrastructural aspects of high capacity calcium sequestration. New Phytol 161:435-448

Meric C (2009) Calcium oxalate crystals in some species of the Tribe Inuleae (Asteraceae). Acta Biol Cracov Ser Bot 51(1):105-110

Nakata PA (2003) Advances in our understanding of calcium oxalate crystal formation and function in plants. Plant Sci 164:901-909

Nakata PA (2012) Engineering calcium oxalate crystal formation in arabidopsis. Plant Cell Physiol 53(7):1275-1282

Pennel RI, Knox JP, Scofield GN, Selvendran R, Roberts K (1989) A family of abundant plasma membrane-associated glycoproteins related to the arabinogalactan proteins is unique to flowering plants. J Cell Biol 108:1967-1977

Pereira AM, Pereira LG, Coimbra S (2015) Arabinogalactan proteins: rising attention from plant biologists. Plant Reprod 28:1-15

Pereira AM, Lopes AL, Coimbra S (2016) Arabinogalactan proteins as interactors along the crosstalk between the pollen tube and the female tissues. Front Plant Sci 7(1895):1-15

Raman V, Horner HT, Khan IA (2014) New and unusual forms of calcium oxalate raphide crystals in the plant kingdom. J Plant Res 127:721-730

Ruiz N, Ward D, Saltz D (2002) Calcium oxalate crystals in leaves of Pancratium sickenbergeri: constitutive or induced defence? Funct Ecol 16:99-105

Seifert GJ, Roberts K (2007) The biology of arabinogalactan proteins. Ann Rev Plant Biol 58:137-161

Showalter AM (2001) Arabinogalactan-proteins: structure, expression and function. Cell Mol Life Sci 58:1399-1417

Tooulakou G, Giannopoulos A, Nikolopoulos D, Bresta P, Dotsika E, Orkoula MG, Kontoyannis CH, Fasseas C, Liakopoulos G, Klapa MI, Karabourniotis G (2016) Alarm Photosynthesis: Calcium oxalate crystals as an internal $\mathrm{CO}_{2}$ source in plants. Plant Physiol 171:2577-2585

Webb MA, Cavaletto JM, Carpita NC, Lopez LE, Arnott HJ (1995) The intravacuolar organic matrix associated with calcium oxalate crystals in leaves of Vitis. Plant J 7(4):633-648

Yates EA, Valdor J, Haslam SM, Morris HR, Dell A, Mackie W et al (1996) Characterization of carbohydrate structural features recognized by anti-arabinogalactan-protein monoclonal antibodies. Glycobiology 6:131-139 